Madrygal. Revista de Estudios Gallegos

ISSN: 1138-9664

http://dx.doi.org/10.5209/MADR.57648

\title{
Maria Mercè Marçal, unha pequena escolma
}

Eduard del Castillo Velasco

Aínda que naceu accidentalmente en Barcelona no ano 1952, Maria-Mercè Marçal pasou a infancia en Ivars d'Urgell, de onde proviña a familia, e sempre se sentiu desta vila de tradición agraria da Cataluña occidental. Despois de estudar o bacharelato en Lleida, volveu á capital para estudar Filoloxía Clásica e axiña se implicou na esquerda independentista e no feminismo. Como escritora comprometida coa recuperación da obra e da memoria das mulleres creadoras, así como co fomento da visibilidade das súas contemporáneas, foi unha das impulsoras do Comité de Escritoras do Centro Catalán do PEN. Alén da actividade literaria, foi catedrática de instituto de lingua e literatura catalás. A

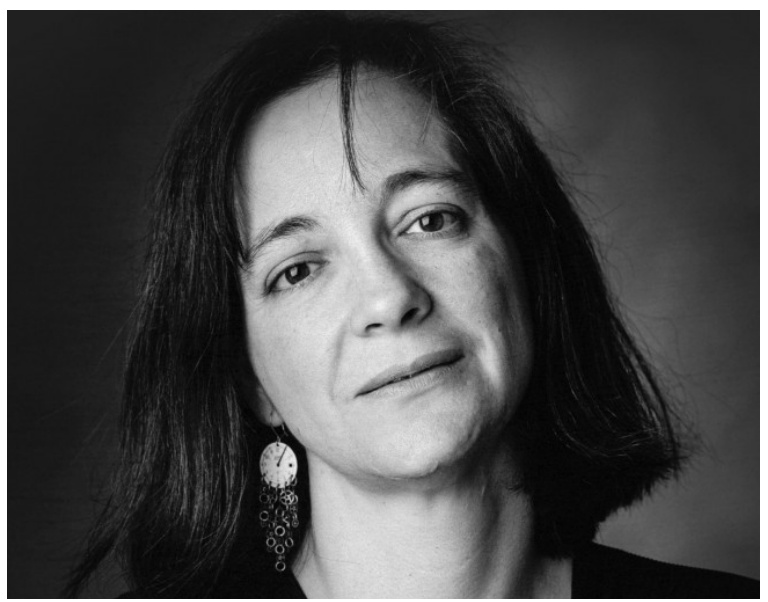

Foto: Rafael Vargas súa filla Heura -nada en 1980 e cuxa crianza afrontou en solitario-, cualificouna como grafómana porque ademais da produción poética, con algunha publicación póstuma, traduciu autoras como Marguerite Yourcenar, publicou unha novela, La passió segons Renée Vivien, e cultivou a prosa ensaística, recollida en gran parte no volume Sota el signe del drac. No ano 2014, Edicions 62 recolleu en El senyal de la pèrdua os escritos inéditos dos últimos anos (un dietario intermitente e interrompido, e a correspondencia con Jean-Paul Goujon, biógrafo de Renée Vivien), uns textos atravesados pola experiencia da enfermidade. Foi tamén unha das fundadoras, en 1973, da editorial Llibres del Mall, onde apareceu a primeira edición (bilingüe galego-catalán) d'A illa das mulleres loucas de Alfonso Pexegueixo. A súa poética bebe da tradición oral, das cancións e da cultura popular que lle foi transmitida na familia, especialmente durante os anos de infancia en Ivars d'Urgell. En canto á lingua, o seu estilo pódese conectar cunha tradición medieval que J. V. Foix recuperou a principios do século XX e que está marcada por un vocabulario rico, culto e popular ao tempo, e un imaxinario poboado de elementos mitolóxicos e simbólicos que ela enriqueceu con elementos da vida cotiá tradicionalmente asociados ás mulleres e arredados ata entón da poesía. Ademais, tratou mediante formas poéticas tradicionalmente masculinas (sonetos, sextinas...) temas como a maternidade - cun enfoque novidoso e antipatriarcal- ou a sexualidade non normativa. Un exemplo son as sextinas de Terra de mai, nos que aborda por primeira vez o amor lésbico na literatura catalá. Vítima do cancro, morreu en 1998, aos 45 anos, en Barcelona. 
Dividimos esta escolma en tres apartados. En primeiro lugar, damos a tradución ao galego dos dous poemas que a poeta titulou como "Divisa", pola súa popularidade e a ampla difusión que tiveron (especialmente o primeiro, feito emblema da loita feminista e do independentismo de esquerdas). En segundo lugar, traducimos a terceira parte dun dos seus poemarios máis coñecidos, Bruixa de dol, moi divulgado grazas ás sucesivas edicións escolares. Finalmente, pola importancia que xa apuntamos anteriormente, incluímos unha das sextinas do poemario Terra de Mai.

\section{As DIVISAS}

\section{Divisa}

Al'atzar agraeixo tres dons: haver nascut dona, de classe baixa i nació oprimida.

I el tèrbol atzur de ser tres voltes rebel.

\section{Divisa}

Ao azar agradezo tres dons: ter nacido muller, de clase baixa e nación oprimida.

E o turbio azur de ser tres voltas rebelde.

De Cau de Llunes (Proa, 1977)

\section{Divisa}

Enmarco con catro madeiras

un anaco de ceo e cólgoo na parede.

Eu teño un nome

e con xiz escríboo embaixo.

De Bruixa de dol (Llibres del Mall, 1979)

\section{FOGUEIRA XOANA}

\section{I}

Damunt un cel de fil

amb unes vores fetes de coixí,

avui regna la lluna, amor,

i cap flor no es tanca.

\section{II}

Amic, et citaré al cor d'una petxina.

Petit ocell, ajoca't en el pit de l'onada.

Dóna'm la llengua, amor. Dóna'm la sal.

I dóna'm també

aquest dolç llangardaix que en duu follia quan s'enfila per l'herba.

Ben a pleret, que ens hi atrapi l'alba.
I

Sobre un ceo de fío

cunhas dobras tecidas con encaixes, hoxe reina a lúa, amor, e ningunha flor se pecha.

\section{II}

Amigo, citareite no corazón da cuncha.

Déitate, paxariño, no peito dunha onda. Meu amor, dáme a lingua. Dáme o sal.

E dáme tamén este doce lagarto que me alouca ao rubir pola herba.

Ben devagar, que nos atrape a alba. 


\section{III}

Els meus pits són dos ocells engabiats quan els teus dits els cerquen

per entre les fulles i les flors del vestit.

Però quan fulles i flors cauen a terra -que el desig porta dalla!són dos peixos que et fugen de les mans en les crestes nevades de la mar.

IV

Dolç enemic, amb caçapapallones

em pares trampes

pels plecs del plaer.

V

Avui tancaria el llangardaix en una gàbia.

I que fos la festa dels dits, la dansa de l'heura a cau d'orella, la tendresa de la planta dels peus, l'or negre de cella i de l'aixella.

Seguiria els camins que el deliri oblida amb pas molt lent

com el del bou que llaura

aquest paisatge de lluna gitana.

\section{VI}

Si algú em deia que la teva espasa

no enduraria tres guerres,

-ni tan sols tres batalles seguides!-

li reconeixeria el fet

sense gens de recança.

Però si algú gosés dir

que hi ha joguina més dolça

sobre la terra,

que li caiguin de cop totes les dents

per mentider!

\section{III}

Os meus peitos son dous paxaros engaiolados cando os teus dedos buscan neles

por entre as follas e as flores do vestido.

Mais cando follas e flores caen ao chan -leva gadaña o desexo!-son dous peixes que che foxen das mans nas cristas nevadas do mar.

IV

Doce inimigo

con cazabolboretas

que me pos trampas

nos pregos do pracer.

\section{V}

Hoxe encerraría nunha gaiola o lagarto.

E que fose a festa dos dedos, a danza da hedra falando ao ouvido, a tenrura da planta dos pés, o ouro negro da cella e da axila.

Seguiría os camiños que o delirio esquece con paso moi lento coma o do boi que labra esta paisaxe de lúa xitana.

\section{VI}

Se alguén me dixese que a túa espada non aturaría tres guerras -nin sequera tres batallas seguidas!recoñeceríalle o feito sen nada de pesar.

Mais se ousase alguén dicir que hai un xoguete máis doce riba da terra, que lle caian de vez todos os dentes por mentireiro! 


\section{VII}

Perquè venies sense armes

t'he obert les set portes del castell

i cap guaita no he deixat rere els merlets.

I he llençat l'anell a l'aigua

perquè un peix, o la lluna,

el guardi en el seu ventre.

\section{VIII}

La lluna, guaita

del nostre castell casolà,

avui ens té enveja.

Més lívida que l'herba

ja va a minvant

com minva tota cosa

IX

\section{Lluna negra}

Veniu, a pler, records

$i$ atieu la foguera

-la foguera joana

Tot aquest bosc

ja només és estelles

i el llenyataire

ha perdut els passos.

Cal canviar de pressa el decorat

perquè pugui florir a temps la berbena.

\section{VII}

Porque chegabas sen armas

abrinche as sete portas do castelo

e non deixei sentinelas tras das ameas.

E guindei o anel á auga

para que un peixe, ou a lúa,

o garde no seu ventre.

\section{VIII}

A lúa, vixía

do noso castelo caseiro,

tennos hoxe envexa.

Máis lívida ca a herba

vai xa minguante

como mingua toda cousa.

\section{IX}

\section{Lúa negra}

Vide a pracer, lembranzas

e atizade a fogueira

-a fogueira xoana

Toda esta fraga

xa é tan só estelas

e o leñador

perdeu os pasos.

Cómpre cambiar axiña o decorado

para que a tempo floreza a verbena.

De Bruixa de dol (Llibres del Mall, 1979) 


\section{Unha sextina de TERRA DE MAI}

\section{De parar i desparar taula}

Amor, saps?, tot avui, la meva porta frisant per fer-te pas s'obria sola. S'han omplert de viandes plats i taula. Tot resplendia en els cristalls de l'aigua. El julivert s'ha refet. (El rellotge toca les cinc. Vindràs?) Tota la casa,

avui no sembla la mateixa casa. Creix l'orenga i s'enfila per la porta. La fruita accepta el repte del rellotge. (Ja ho sé: les sis, i encara parlo sola!) A l'aigüera vessunya un somni d'aigua i plou desig a raig sobre la taula.

Amor... (Les set: no véns. Sota la taula s'amaguen els neguits. Fora de casa, la tristesa!) Quin goig els dits de l'aigua acaronant rajoles! Pany i porta com floriran quan tu arribis! Solament vull que calli aquest rellotge.

Toquen dos quarts de vuit. Sóc el rellotge que amb minuts i segons paro la taula.

Toco les vuit i, del cap a la sola de la sabata, sento que la casa ja no sé si és meva. Per la porta fuig, enyorat, el cor desfet de l'aigua.

Toco les nou i les deu, i sóc l'aigua gebrada a les agulles del rellotge. Amunt i avall ja no sóc jo qui em porta. Per encobrir neguits ja no tinc taula. Trenco el mirall i em rediu que sóc sola. Puja el desig i clivella la casa.

Per les escletxes, veus?, fujo de casa, raiera d'aquest foc que invoca l'aigua. (Vindràs quan morirà l'hora més sola?) La fruita perd l'aposta amb el rellotge i la tardor fa el ple damunt la taula. Res no troba sortida per cap porta.

\section{De poñer e recoller a mesa}

Sabes, amor?, todo hoxe, a miña porta ansiando darche paso abríase soa.

Encheron as viandas prato e mesa. Todo brillaba nos cristais da auga. O pirixel refíxose. (O reloxo toca as cinco. Vas vir?) Toda esta casa,

hoxe non asemella a mesma casa. Medra o ourego e medra pola porta. A froita acepta o reto do reloxo. (Xa o sei: as seis, e aínda falo soa!) No vertedoiro reve un soño de auga, chove desexo a cachón sobre a mesa.

Amor... (As sete: non vés. Baixo a mesa agóchase a inquedanza. Alén da casa, a tristura!) Que gozo os dedos da auga a cofar azulexos! Pomo e porta como han florecer cando chegues! Soamente quero que cale este reloxo.

As sete e media. Son eu o reloxo que minuto a segundo poño a mesa. Toquei as oito e, da cabeza á sola do meu zapato, sinto que esta casa non sei se é miña. Foxe pola porta, saudoso, o corazón desfeito da auga.

Toco as nove e as dez, e son a auga xeada nas agullas do reloxo.

Aquí e alá non son xa eu quen me porta. Non dá encuberto inquedanzas a mesa. Rompo o espello e insiste en que estou soa. Sobe o desexo e agrétase a casa.

Polas fendas, non ves?, fuxo da casa, o lume no que remo invoca a auga. (Virás cando ha morrer a hora máis soa?) A froita perde a aposta co reloxo e o outono señorea sobre a mesa. Non hai saída por ningunha porta. 
La nit truca a la porta $i$ ve ben sola: desparo taula i nego dins de l'aigua desig, rellotge, orenga, plats, cor, casa.
A noite peta á porta e vén ben soa: recollo a mesa e anego na auga desexo, reloxo, ourego, pratos, corazón, casa.

De Terra de Mai (El Cingle, 1982) 